\title{
OS GASTOS DE UMA NOVA IDEIA - OS BENEFÍCIOS DE INICIAR UMA EMPRESA EM UMA INCUBADORA DE BASE TECNOLÓGICA
}

\author{
EXPENDITURES A NEW IDEA - THE BENEFITS OF STARTING A NEW \\ BUSINESS IN A TECHNOLOGY-BASED INCUBATOR
}

\author{
Carlos Henrique Da Mota Couto \\ Faculdade Metodista Granbery - Juiz de Fora - MG \\ carlosmotacouto@hotmail.com
}

Antônio Augusto Brion Cardoso Universidade Federal de Juiz de Fora - UFJF gutobrion@gmail.com

Anderson Henrique de Lima Faculdade Metodista Granbery - Juiz de Fora - MG anderson_hl@hotmail.com

Submissão: $23 / 03 / 2016$

Aprovação: 19/09/2017

\begin{abstract}
RESUMO
Este artigo propõe uma comparação entre iniciar uma empresa diretamente no mercado em relação a iniciar em uma incubadora e relacionar os custos envolvidos neste processo. Para isto, no referencial teórico são apresentados os conceitos de empreendedorismo, burocracia para abertura de empresas, custos de abertura de empresa, incubadora de empresa e contabilidade de custos. Buscando confrontar a teoria com a prática, uma pesquisa do tipo estudo de caso foi realizada dentro de uma incubadora de empresas, o Centro Regional de Inovação e Transferência de Tecnologia (CRITT) da Universidade Federal de Juiz de Fora (UFJF). Os resultados obtidos com a pesquisa juntamente com a base teórica explorada, objetivam tornar este estudo uma ferramenta de auxílio aos indivíduos que tenham uma ideia inovadora e que almejam abrir uma empresa, tornando-se empreendedores.
\end{abstract}

PALAVRAS-CHAVE: Empreendedorismo. Incubadora de empresas. Custos e abertura de empresa. 


\begin{abstract}
This article proposes a comparison between starting a business directly in the market in relation to open in an incubator and relate the costs involved in this process. For this, the theoretical framework presents the concepts of entrepreneurship, bureaucracy to start a businesses, businesses startup costs, business incubator and cost accounting. Seeking to confront theory with practice, a survey of the type case study was carried out within a business incubator, the Centro Regional de Inovação e Transferência de Tecnologia (CRITT) of the Universidade Federal de Juiz de Fora (UFJF). The results of the survey together with the theoretical basis explored aim to make this study an aid tool for individuals who have an innovative idea and that aims to start a business and become entrepreneurs.
\end{abstract}

KEY-WORDS: Entrepreneurship. Business incubator. Costs and company opening. 


\section{INTRODUÇÃO}

O atual cenário econômico e social, aliado aos incentivos oriundos de diversas organizações e órgãos governamentais tem favorecido cada vez mais o empreendedorismo no Brasil. Nesse contexto, conhecer todos os custos envolvidos no desenvolvimento de produtos e serviços, assim como, os incorridos na abertura de uma empresa, torna-se uma ferramenta de auxílio às pessoas que pretendem abrir o próprio negócio. De forma a favorecer e incentivar a abertura de empresas, existem algumas ações que trazem facilidade para que as ideias inovadoras se transformem em produtos e serviços. Uma dessas opções disponíveis está nas incubadoras de empresas, que segundo o CRITT (2014) são ambientes especialmente planejados com o propósito de apoiar iniciativas empreendedoras e projetos inovadores, facilitando o seu desenvolvimento por meio do oferecimento de infraestrutura, serviços especializados e assessoria gerencial.

Neste escopo, o presente estudo tem por objetivo identificar os possíveis benefícios de se iniciar um negócio em uma incubadora de empresas.

De modo a facilitar o entendimento do estudo, primeiramente, trata-se do termo custo, conforme salientam Bruni e Famá (2008) o termo custo tem sua terminologia contábil envolvida em uma questão que é fazer a distinção entre custos e despesas. Na visão destes autores, de modo geral, os custos são consumidos no processo de produção e armazenados em forma de estoque, ao passo que, as despesas são relacionadas ao período não sendo adotadas na elaboração de produtos e serviços. Corroborados pela classificação de Martins (2008) que usa a palavra custo para gastos relativos ao que foi consumido na produção e despesa como gasto relativo ao esforço de vendas, desembolsos administrativos e financiamentos. O estudo irá nortear-se por esta diferenciação.

O trabalho apresenta uma revisão bibliográfica sobre empreendedorismo, inovação e o processo formal de abertura de empresas no Brasil, descrevendo o processo burocrático que envolve esta questão.

A metodologia desenvolvida teve uma abordagem qualitativa, do tipo exploratória em sua fase inicial, que pode ser entendida na visão de Cervo e Bervian (2002, p.69) como uma pesquisa que "realiza descrições precisas da situação e quer descobrir as relações existentes entre os elementos componentes da mesma" e de acordo com Malhotra et al. (2005, p.56) o seu objetivo é "explorar ou examinar um problema ou situação para proporcionar conhecimento e compreensão". Desta forma, observa-se que quando ainda não se tem o conhecimento e a compreensão dos fenômenos estudados, esta torna-se mais adequada ao propósito. Em um segundo momento faz-se uso do método descritivo, que observa, analisa e correlacionam os fenômenos, no entanto, sem fazer algum tipo de manipulação nos mesmos (CERVO; BERVIAN, 2002) ao analisar os resultados obtidos na pesquisa.

O tipo de pesquisa descritiva utilizado neste trabalho foi o estudo de caso que na visão de Yin (2005) pode ser entendida como uma investigação empírica de fenômeno contemporâneo dentro de seu contexto da vida real. A pesquisa foi realizada na incubadora de base tecnológica da Universidade Federal de Juiz de Fora (UFJF) localizada no município de Juiz de Fora, Estado de Minas Gerais, analisando os dados obtidos e identificando os benefícios de se optar por este caminho para dar início a uma empresa em conformidade com os conceitos da estrutura conceitual apresentada.

\section{FUNDAMENTAÇÃO TEÓRICA}


O embasamento teórico desdobra-se em cinco principais pontos de investigação: empreendedorismo, englobando neste, um breve histórico do empreendedorismo no mundo e no Brasil, bem como as características e o perfil dos empreendedores; procedimentos para abrir uma empresa; incubadoras de empresas, com definições, histórico e contabilidade de custos, apresentando a terminologia de custos e gastos.

\subsection{Empreendedorismo}

O termo empreendedorismo segundo Dolabela (2008) é a tradução da palavra entrepreneurship, a qual contém as ideias de iniciativa e inovação, ou seja, um termo que reflete a personalidade do indivíduo, o modo como este percebe o mundo e a sua forma de se relacionar. Destaca-se que o empreendedorismo empresarial, objeto deste estudo, é apenas uma das infindáveis formas de se empreender.

Dornelas (2005) entende que o empreendedorismo resulta da sinergia e do envolvimento de pessoas e processos que juntos realizam a transformação de ideias em negócios e tendo a perfeita implementação destas oportunidades como o caminho para a criação de uma atividade de sucesso.

Desta forma, o conceito relaciona-se de maneira geral com indivíduos que possuem alguma ideia, que pode ser completamente inovadora ou não, como uma melhora de um serviço/produto ou, até mesmo, um processo já existente e dedicam-se a implementá-la, transformando-a em um novo negócio ou transformando um negócio existente.

Uma das mais antigas definições de empreendedor e que sintetiza bem a essência destes indivíduos é a de Schumpeter (1949, apud DORNELAS, 2005, p.39).

O empreendedor é aquele que destrói a ordem econômica existente pela introdução de novos produtos e serviços, pela criação de novas formas de organização ou pela exploração de novos recursos e materiais.

Degen (2009, p.8) corrobora com a visão de Schumpeter (1949) ao dizer que empreendedor "é aquele que tem a visão do negócio e não mede esforço para realizar o empreendimento. A sua realização é ver sua ideia concretizada em seu negócio".

Para entender melhor o significado de empreendedor, torna-se necessário descrever as características que envolvem os empreendedores, bem como as motivações que fazem com que se lancem no mercado com a sua própria empresa.

O empreendedor como indivíduo possui características e habilidades especificas que o definem como um empreendedor propriamente dito. As pesquisas que abrangem esta temática encontram pontos de convergência desses atributos, que apesar de não possuírem conotações determinísticas, tem contribuído para a identificação e compreensão do comportamento empreendedor (DOLABELA, 2008).

Dornelas (2005) salienta que um conjunto de características pessoais aliadas a características sociológicas e ambientais permitem o nascimento de uma nova empresa proveniente destes indivíduos.

Assim, pode-se dizer que um indivíduo que deseja se tornar um empreendedor de sucesso deve aliar as características de sua personalidade, que podem ser inatas ao indivíduo ou adquiridas ao longo de sua vida, com fatores ambientais em conjunto com as oportunidades de mercado.

Os empreendedores podem ser voluntários, quando o indivíduo tem vontade e motivação para empreender, ou involuntários quando estes são forçados por situações adversas e independentes de sua vontade como desemprego e imigrações, por exemplo 
(DOLABELA, 2008). O quadro 1, abaixo, ilustra características dos empreendedores de sucesso.

Quadro 1 - Características dos Empreendedores de Sucesso

\begin{tabular}{|c|c|}
\hline Visionários & $\begin{array}{l}\text { Eles têm a visão de como será o futuro para seu negócio e sua vida, e } \\
\text { o mais importante: eles têm a habilidade de implementar seus sonhos; }\end{array}$ \\
\hline $\begin{array}{l}\text { Sabem tomar } \\
\text { decisões }\end{array}$ & $\begin{array}{l}\text { Não se sentem inseguros, sabem tomar decisões corretas na hora } \\
\text { certa, principalmente em momentos de adversidades. }\end{array}$ \\
\hline Fazem a diferença & $\begin{array}{l}\text { Sabem agregar valor aos serviços e produtos que colocam no } \\
\text { mercado; }\end{array}$ \\
\hline $\begin{array}{l}\text { Exploraram ao } \\
\text { máximo as } \\
\text { oportunidades }\end{array}$ & $\begin{array}{l}\text { Para os empreendedores, as boas ideias são geradas daquilo que todos } \\
\text { conseguem ver, mas não identificam algo prático para transformá-las } \\
\text { em oportunidades. Neste ponto entra a inovação. }\end{array}$ \\
\hline $\begin{array}{l}\text { São determinados } \\
\text { e dinâmicos }\end{array}$ & $\begin{array}{l}\text { Implementam suas ações com total comprometimento. Mantêm-se } \\
\text { dinâmicos e cultivam certo inconformismo diante da rotina; }\end{array}$ \\
\hline São dedicados & $\begin{array}{l}\text { Eles se dedicam integralmente ao seu negócio. Comprometem o } \\
\text { relacionamento com amigos, com a família e até mesmo com a } \\
\text { própria saúde. São incansáveis e loucos pelo trabalho; }\end{array}$ \\
\hline $\begin{array}{l}\text { São otimistas e } \\
\text { apaixonados pelo } \\
\text { que fazem }\end{array}$ & $\begin{array}{l}\text { Eles adoram o trabalho que realizam. O otimismo faz com que } \\
\text { enxerguem o sucesso, em vez de imaginar o fracasso; }\end{array}$ \\
\hline $\begin{array}{l}\text { São independentes } \\
\text { e constroem o } \\
\text { próprio destino }\end{array}$ & $\begin{array}{l}\text { Querem ser independentes, em vez de empregados, querem criar algo } \\
\text { novo e determinar os próprios passos, abrir os próprios caminhos, ser } \\
\text { o próprio patrão e gerar empregos; }\end{array}$ \\
\hline $\begin{array}{l}\text { Assumem riscos } \\
\text { calculados }\end{array}$ & $\begin{array}{l}\text { Assumem riscos calculados e sabem gerenciar o risco, avaliando as } \\
\text { reais chances de sucesso. Assumir riscos tem relação com desafios. }\end{array}$ \\
\hline $\begin{array}{l}\text { São líderes e } \\
\text { formadores de } \\
\text { equipes }\end{array}$ & $\begin{array}{l}\text { Os empreendedores têm um senso de liderança incomum. São } \\
\text { respeitados e adorados pelos seus funcionários, pois sabem valorizá- } \\
\text { los, estimulá-los e recompensá-los, formando um time em torno de si; }\end{array}$ \\
\hline $\begin{array}{l}\text { São bem } \\
\text { relacionados } \\
\text { (networking) }\end{array}$ & $\begin{array}{l}\text { Sabem construir uma rede de contatos que os auxiliem no ambiente } \\
\text { externo da empresa, junto a clientes, fornecedores e entidades de } \\
\text { classe; }\end{array}$ \\
\hline $\begin{array}{l}\text { Criam valor para } \\
\text { a sociedade }\end{array}$ & $\begin{array}{l}\text { Utilizam seu capital intelectual para criar valor para a sociedade, com } \\
\text { a geração de empregos, dinamizando a economia e inovando. }\end{array}$ \\
\hline $\begin{array}{l}\text { Planejam, } \\
\text { planejam, } \\
\text { planejam. }\end{array}$ & $\begin{array}{l}\text { Planejam cada passo de seu negócio, desde o primeiro rascunho do } \\
\text { plano de negócios, até a apresentação do plano a investidores, } \\
\text { definição das estratégias de marketing do negócio, sempre tendo } \\
\text { como base a forte visão de negócio que possuem; }\end{array}$ \\
\hline $\begin{array}{l}\text { Possuem } \\
\text { conhecim }\end{array}$ & $\begin{array}{l}\text { São sedentos por saber e aprender continuamente, pois sabem que } \\
\text { quanto maior o domínio sobre um ramo de negócio, maior é a sua } \\
\text { chance de êxito; }\end{array}$ \\
\hline
\end{tabular}

Fonte: Adaptado de Dornelas (2005, p. 33 a 34).

O quadro anterior nos apresentou características dos empreendedores, que podem ser de indivíduos que desejam ter a sua própria empresa ou apenas mudar um processo de sua rotina de trabalho, independente da sua área de atuação, ou seja, não são características exclusivas dos empreendedores que objetivam ter o próprio negócio.

A concepção do termo "empreendedor empresarial" advém dos estudos e teorias dos economistas sobre este tema que na concepção de Dolabela (2008) possui os seguintes pontos: 
- Indivíduo que cria uma empresa, qualquer que seja ela;

- Pessoa que compra uma empresa e introduz inovações, assumindo riscos, seja na forma de administrar, seja na forma de vender, fabricar, distribuir ou fazer propaganda de seus produtos e/ou serviços, agregando novos valores; e

- Empregado que introduz inovações em uma organização, provocando o surgimento de valores adicionais. (DOLABELA, 2008, p. 25).

Como destacado pelo autor, este perfil de empreendedor abrange os indivíduos que necessariamente iniciam ou adquirem uma empresa. No caso de empresas adquiridas torna-se necessário que alguma inovação seja introduzida na sua operação para o indivíduo tornar-se um empreendedor.

\subsubsection{Histórico do surgimento do empreendedorismo}

O trabalho apresenta brevemente o histórico deste fenômeno no mundo e no Brasil, pretendendo-se buscar um elo com o surgimento de um tipo específico de organização, que será objeto do estudo de caso e do próximo tópico, a Incubadora de Empresas, visto que, o nascimento desta organização está diretamente relacionado com a difusão do movimento empreendedor no Brasil.

De acordo com Dornelas (2005) o primeiro exemplo do termo empreendedorismo pode ser creditado a Marco Polo, no momento em que este tentou estabelecer uma rota para o Oriente. Seu papel de empreendedor deu-se no momento em que ele assinou um contrato com uma pessoa que possuía dinheiro, hoje denominado de capitalista ou investidor, para vender as mercadorias deste que assumia os riscos de forma passiva, ficando a cargo de Marco Polo os riscos físicos e emocionais desta operação, deixando a cargo dele o papel ativo do negócio. A partir da Idade Média, o termo empreendedor passou a ser usado para caracterizar o indivíduo que gerenciava grandes projetos de produção, onde este não assumia grandes riscos, apenas gerenciava os projetos de acordo com os recursos disponíveis.

Ainda segundo Dornelas (2005) no século XVII ocorrem os primeiros indícios da relação assumir riscos e empreendedorismo, onde o empreendedor estabelecia um acordo com o governo para a realização de algum serviço ou fornecimento de algum produto. Durante o século seguinte houve uma diferenciação de fato do capitalista e do empreendedor devido ao processo de industrialização que ocorria no mundo.

No final do século XIX, os empreendedores eram constantemente confundidos com os gerentes ou administradores, do ponto de vista econômico, pois, a estes era dado a incumbência de organizar, controlar, dirigir e planejar as ações da empresa, sendo estes funcionários do capitalista, isto é, não eram donos do próprio negócio. (DORNELAS, 2005)

Como observa-se, a história do empreendedorismo se entrelaça com a história das relações comerciais da humanidade.

\subsubsection{Movimento empreendedor no Brasil}

Sobre o movimento empreendedor no nosso país, Dornelas (2005) relata que este movimento começou a tomar forma na década de 1990, tendo apoio de entidades como Serviço Brasileiro de Apoio à Micro e Pequenas Empresas (SEBRAE) e da Sociedade Brasileira para Exportação de Software (SOFTEX) que foram criadas neste período. Num momento anterior pouco se falava em empreendedorismo ou em criação de pequenas empresas devido ao ambiente político e econômico que o Brasil se encontrava. Aliado a estas questões, outro fator que inibia o empreendedorismo era um cenário de falta de informações que auxiliassem na jornada empreendedora. 
Ressaltando o papel destas duas entidades, o autor ainda destaca o principal foco de atuação destas. O SEBRAE atua como o principal órgão conhecido dos pequenos empresários, onde estes buscam informações sobre abertura de empresa, bem como, consultoria para resolver problemas pontuais. Já a SOFTEX tem sua origem entrelaçada com o histórico do empreendedorismo no Brasil na década de 1990, e tem a finalidade de levar empresas de softwares do país ao mercado externo, propiciando aos empresários deste setor capacitação em gestão e tecnologia.

Os programas criados por estas entidades em todo país, junto a incubadoras de empresas e universidades, contribuíram para que o tema empreendedorismo fosse difundido.

É importante ressaltar que anteriormente a este período não significa que não existiram empreendedores no país, mesmo sem conhecerem formalmente os conceitos de marketing, finanças, gestão e outros temas pertinentes da área empresarial. Pode-se destacar que alguns empresários como o industrial Francisco Matarazzo, e tantos outros contribuíram para o desenvolvimento econômico do país sendo estes considerados como empreendedores brasileiros (MENEZES, 2012).

\subsection{Abertura de empresas no Brasil}

Segundo a Federação das Indústrias do Estado do Rio de Janeiro (FIRJAN) "A burocracia é um sistema composto por regras e procedimentos importantes para orientar a sociedade. Contudo, em excesso, ela se torna extremamente prejudicial ao desenvolvimento econômico do país, diminuindo sua competitividade" (FIRJAN, 2010, p.4). A entidade afirma ainda que "O processo de abertura de empresas no país é hoje uma verdadeira peregrinação entre órgãos, pouco transparente e muito custoso" (FIRJAN, 2010, p.4).

Dessa maneira, os processos burocráticos, afetam os empresários do país não só no seu dia a dia, mas também no processo de início e eventual encerramento de atividades de sua empresa.

Outro fator que reflete o excesso de burocracia na abertura de uma empresa no Brasil é o tempo médio que o futuro empreendedor gasta com todo o processo. Segundo dados do Doing Business (BANCO MUNDIAL, 2014), um empreendedor demora em média 107 dias para abrir uma empresa no Brasil.

No entanto, segundo informações da Secretaria da Micro e Pequena Empresa da Presidência de República (SMPE), nos últimos anos o país está adotando medidas que visam a desburocratizar o processo de abertura de empresas no país, como exemplo a Lei 147/14, sancionada em agosto do ano de 2014, na qual estavam contidas, medidas que visam melhorar o processo de abertura e fechamento de empresas no Brasil, beneficiando, inicialmente, mais 450 mil empresas com faturamento anual de até $\mathrm{R} \$ 3,6$ milhões (SMPE, 2015).

O SEBRAE do Rio Grande do Sul resume em sete passos todo o processo pelo qual os empreendedores devem passar ao decidirem abrir uma empresa no Brasil. A figura 1, abaixo, representa cada uma dessas etapas: 
Figura 1: 7 passos para abrir minha empresa - SEBRAE - RS.

\begin{tabular}{|c|c|c|c|c|c|c|c|}
\hline \multicolumn{8}{|c|}{$1^{\circ}$ PASSO - INFORMAC̣ÖES BÁSICAS PARA ABRIR UMA EMPRESA } \\
\hline 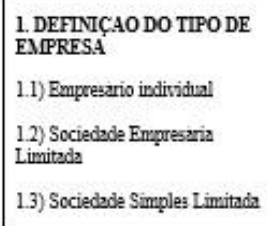 & $\begin{array}{l}\text { 2. TIPOS DE } \\
\text { PARTICIPAÇAO } \\
\text { 2.1) Socio } \\
\text { ziministrador } \\
\text { 2.2) Socio quotista }\end{array}$ & $\begin{array}{l}\text { 3. SII } \\
\text { OU D } \\
1.1) \\
1.2) \mathrm{A} \\
\text { 1.3) P } \\
\text { empre }\end{array}$ & 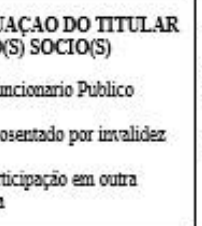 & $\begin{array}{l}\text { 4. NOMES } \\
\text { 4.1) Nome } \\
\text { Fartasia } \\
\text { 4.2) Nome } \\
\text { Engresarial }\end{array}$ & $\begin{array}{l}\text { 5. CAPITAL } \\
\text { SOCIAL }\end{array}$ & 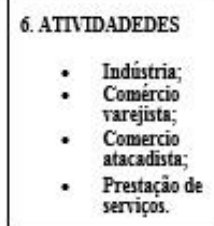 & $\begin{array}{l}\text { 7. COPLAS DE DOCUMINTTOS } \\
\text { 2.1) Copia sutenticada do RG e CPF } \\
\text { do titular ou dos socios. } \\
\text { 2.2) Copia do comprovante do } \\
\text { endereço do empresa }\end{array}$ \\
\hline \multicolumn{3}{|c|}{$\begin{array}{l}\text { Consulta prévia da situaç̃ão dos sócios, pesquisar o nome } \\
\text { da futura empresa, pedir o boletim informativo do } \\
\text { imóvel onde o negócio irá funcionar e consultar licenças } \\
\text { necessárias. }\end{array}$} & \multicolumn{5}{|c|}{$\begin{array}{l}\text { - Receita Federal } \\
\text { Junta Comercial Do Estado } \\
\text { : Secretaria Estadual Da Fazenda } \\
\text { Secretaria Municipal Da Fazenda } \\
\text { Em alguns casos, Vigilância Sanitar }\end{array}$} \\
\hline \multicolumn{8}{|c|}{$\begin{array}{l}\text { 3. PASSO - REGISTRO DO CONTRATO SOCLAL OU DO REQUERIMENTO DE EMPRES.ंRIO } \\
\text { O Contrato entre os sócios é o ingtrumento que regerá a empresa, motrando as responsabilidades, direitos e deveres de seus membros e de terceiros. Algumas cláusulas } \\
\text { são obrigatórias, outras facultativas. O Contrato Social também faz referência aos dados cadastrais da empresa e das pessoas que compóem a sociedade, bem como as } \\
\text { atividades que serão desenvolvidas pela mesma. }\end{array}$} \\
\hline \multicolumn{8}{|c|}{$\begin{array}{l}4^{\circ} \text { PASSO - CADASTRO NACIONAL DA PESSOA JURIDICA (CNPJ) } \\
\text { O CNPJ é um cadastro expedido pela Receita Federal. Toda Pessoa Juridica (empresa) é obrigada a inscrever-se. Sem o CNPJ, a empresa está impedida de abrir conta } \\
\text { bancária, realizar compras de fornecedores, emitir nota fiscal, participar de licitaçês, obter alvará e os demais registros. }\end{array}$} \\
\hline \multicolumn{8}{|c|}{ 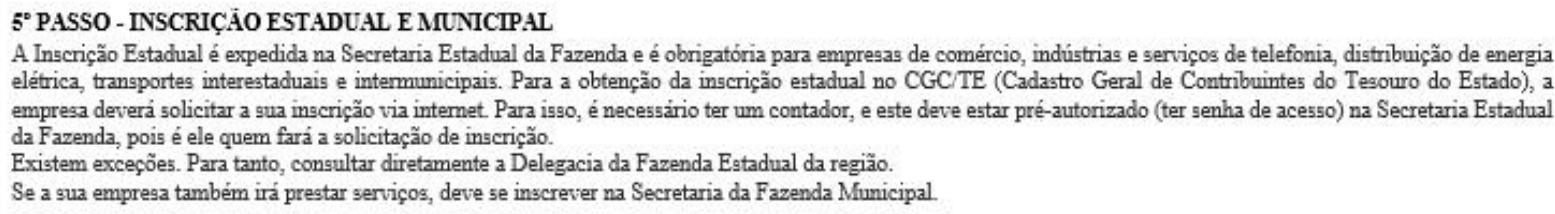 } \\
\hline \multicolumn{8}{|c|}{$\begin{array}{l}6^{\circ} \text { PASSO -REGISTRO DE ALVARA } \\
\text { O penúltimo passo éa inscrição da empresa na Prefeitura do Município para fins de obtenção do Alvará de Fumcionamento. }\end{array}$} \\
\hline \multicolumn{8}{|c|}{$\begin{array}{l}7^{\circ} \text { PASSO - REGISTRO EM SINDICATOS } \\
\text { A legislação sindical em vigor no Pais estabelece a necessidade de coordenação, proteção e representação legal de categorias econômicas ou atividades exercidas pelas } \\
\text { empresas. Cada atividade empresarial possui a sua representação sindical. Identificando a atividade principal da empresa, se identifica o gindicato correspondente a ela. } \\
\text { Para esta entidade é recolhido anualmente, o imposto sindical patronal. }\end{array}$} \\
\hline
\end{tabular}

Fonte: SEBRAE-RS, 2015.

Os passos acima listados servem de guia para atividades essenciais para um novo negócio.

\subsection{Incubadora de empresas}

Ao decidir pela abertura de uma empresa, exige-se do empreendedor decisões referentes à alocação dos recursos disponíveis, que são escassos e limitados, bem como a montagem da equipe de trabalho, com habilidades e competências especificas para alcance dos objetivos pré-estabelecidos no seu plano de negócios, que segundo Degen é:

A descrição, em um documento, da oportunidade de negócio que o candidato a empreendedor pretende desenvolver, como a descrição do conceito do negócio, dos atributos de valor da oferta, dos riscos, da forma como administrar esses riscos, do potencial de lucro e crescimento do negócio, da estratégia competitiva, bem como o plano de marketing e vendas, o plano de operação e o plano financeiro do novo negócio, com a projeção do fluxo de caixa e o cálculo da remuneração esperada, além da avaliação dos riscos e o plano para superá-los. (DEGEN, 2009, p.208).

Segundo Farah, Cavalcanti e Passos (2012), para minimizar os riscos de abertura de um negócio, importantes decisões são tomadas no tocante a escolha da melhor localização 
para implementar o empreendimento, necessidades de apoio e fomento para o desenvolvimento de seu negócio e, também, dos investimentos iniciais necessários. Ainda de acordo com os autores, esta fase inicial de abertura da empresa, carrega os empreendedores de forte ansiedade, cujo efeito pode causar o desvio de atenção do seu objetivo principal, que é tornar a empresa bem-sucedida no mercado, além de provocar a perda de sua criatividade. Desta forma, espera-se que um ambiente mais amigável seja escolhido, objetivando liberar o foco total do empreendedor no desenvolvimento do negócio.

Um ambiente, muito atrativo para esta fase inicial do empreendimento é uma incubadora de empresas. Para Farah, Cavalcanti e Passos (2012, p.186) as incubadoras "são ambientes construídos ou adaptados com fim específico de acomodar empresas em fase inicial de operação. Nesse local, os empreendedores encontrarão uma série de facilidades físicas e serviços de apoio".

Desta forma, pode-se afirmar que o ambiente de uma incubadora, torna-se uma adequada opção para a fase inicial do negócio e posterior desenvolvimento deste.

As incubadoras se subdividem em três tipos, que de acordo com o Ministério da Ciência e Tecnologia (MCT) são:

1) Incubadora de Empresas de Base Tecnológica: É a incubadora que abriga empresas cujos produtos, processos ou serviços são gerados a partir de resultados de pesquisas aplicadas, e nos quais a tecnologia representa alto valor agregado;

2) Incubadora de Empresas dos Setores Tradicionais: É a incubadora que abriga empresas ligadas aos setores tradicionais da economia, as quais detêm tecnologia largamente difundida e queiram agregar valor aos seus produtos, processos ou serviços por meio de um incremento no nível tecnológico empregado. Devem estar comprometidas com a absorção ou o desenvolvimento de novas tecnologias;

3) Incubadora de Empresas Mista: É a incubadora que abriga empresas dos dois tipos anteriormente descritos. (MCT, 1998, apud DORNELAS, 2005, p.15).

As incubadoras de base tecnológica geralmente são patrocinadas por instituições como as universidades e institutos de pesquisa, assim como prefeituras, órgãos estaduais e federais de fomento à atividade empreendedora e à inovação, além de fundações públicas e privadas (FARAH; CAVALCANTI; PASSOS, 2012).

Ainda de acordo com autores acima os principais objetivos das incubadoras são:

- Estimular a transferência de tecnologia das universidades e institutos de pesquisa para as empresas do setor produtivo;

- Apoiar o nascimento e o desenvolvimento de empresas de base tecnológica;

- Contribuir para a criação de inovações tecnológicas;

- Contribuir para a transformação da economia, renovando o tecido econômico regional. (FARAH; CAVALCANTI; PASSOS, 2012, p. 192).

Destarte, salienta-se que incubadoras são criadas e fomentadas por instituições com objetivos específicos que abrangem tanto o desenvolvimento das novas empresas quanto da localidade onde estas estão inseridas oferecendo a estes agentes uma série de vantagens. Desta forma, a escolha correta do local de instalação destas, assim como das empresas que integrarão o grupo de empresas incubadas, permite um maior desenvolvimento das empresas e da localidade no seu entorno, trazendo benefícios para ambos. 
O quadro 2, abaixo, ilustra uma série de benefícios atribuídos às empresas que estão localizadas em uma incubadora.

Quadro 2 - Vantagens que as incubadoras oferecem para as empresas incubadas.

\begin{tabular}{l|l|l|}
$\begin{array}{l}\text { Diminuem os custos } \\
\text { iniciais necessários: }\end{array}$ & $\begin{array}{l}\text { O uso compartilhado de recursos reduz a necessidade de } \\
\text { investimentos pelo empreendedor; }\end{array}$ \\
$\begin{array}{l}\text { O uso de recursos e serviços compartilhados permite que as } \\
\text { empresas possam reduzir seus custos operacionais. Diminuindo } \\
\text { operacionais: }\end{array}$ & $\begin{array}{l}\text { assim necessidade de contratação de pessoal, além de, } \\
\text { compartilhar algumas contas como água e energia elétrica, como } \\
\text { exemplo; }\end{array}$
\end{tabular}

\section{Proporcionam possibilidade de foco no negócio:}

Oferecem meio para a interação e criação de sinergia com outras empresas localizadas na incubadora:

Reduzem tempo de transferência de tecnologia
Como a administração das instalações é realizada pela administração da incubadora, possibilita ao empreendedor dedicar mais tempo ao foco do negócio, principalmente aos relacionados ao desenvolvimento do produto e do mercado;

Ao oferecer interação com outras empresas localizadas na mesma incubadora, possibilita a troca de experiências e solução de problemas com outros empreendedores, fazendo com que haja uma aceleração do processo de aprendizagem destes empreendedores. Outra possibilidade é a criação de sinergia entre produtos;

Devido à proximidade e ao clima receptivo para essas ações podem ter reduzidos os tempos de transferência das universidades e institutos de pesquisa;

\section{Aceleram o tempo de aprendizagem:}

Propiciam imagem e credibilidade:
Pela assessoria prestada por profissionais das áreas de consultoria e treinamento que normalmente são parceiros da incubadora;

A empresa tem a sua imagem associada ao ambiente da incubadora, desta forma uma incubadora bem administrada acabará transferindo a possibilidade de a empresa incubada também passar esta credibilidade para o mercado.

Farah; Cavalcanti e Passos (2012) apresentam, também, alguns benefícios importantes para a comunidade que recebe a instalação de uma incubadora em sua região como constituir um agente de promoção da transformação da economia, efeito positivo ao renovar o tecido industrial e criar empregos, desenvolvimento e riqueza, e constitui ferramenta orientadora do desenvolvimento industrial.

Observa-se que um ambiente propício para o desenvolvimento de uma empresa possibilita uma redução dos riscos de um novo negócio, além de desenvolver a economia regional e possibilitar a transferência e a criação de tecnologias inovadoras, o que permite benefícios para todos envolvidos neste ambiente, bem como, o desenvolvimento econômico do país.

De acordo com os estudos de Jabbour; Dias e Fonseca (2004) as incubadoras apresentam outras funções que as tornam instrumentos catalisadores e fomentadores de sucesso de novos empreendimentos. Funções estas que têm como propósito o auxílio nas respostas às demandas de apoio as ideias inovadoras que chegam até elas, com o intuito de tornar o negócio viável.

Outra vantagem apresentada pelos autores, e de fundamental importância, é o fato de mitigar a taxa de mortalidade entre as empresas. Segundo os dados apresentados no estudo 
destes autores, as taxas de mortalidade de empresas americanas e europeias passam de $70 \%$, contra $20 \%$ detectado nas empresas que passam pelo processo de incubação. Já no Brasil, as incubadoras logram êxito similar ao reduzir a taxa de mortalidade de $80 \%$ nos novos empreendimentos, para 20\% no caso de incubação (JABBOUR; DIAS E FONSECA, 2004).

Para Farah, Cavalcanti e Passos (2012) o conceito de incubadora de empresas, como o conhecemos hoje, teve a sua introdução pioneira na Inglaterra e Estados Unidos na década de 1970 e início da década de 1980. Na Inglaterra com a readaptação de um conjunto de edifícios localizados no centro da cidade para acomodar pequenas empresas e nos Estados Unidos com a criação pioneira das primeiras incubadoras no início da década de 1980 em alguns estados.

Ainda segundo Farah, Cavalcanti e Passos (2012), no Brasil, este movimento iniciou-se no ano de 1984, como resultado de uma ação do Conselho Nacional de Desenvolvimento Cientifico e Tecnológico ( $\mathrm{CNPq}$ ) para o fortalecimento do apoio ao desenvolvimento da inovação no país. No ano de 1985 foi criada a primeira incubadora localizada em instalações adaptadas na cidade de São Carlos estado de São Paulo, a Fundação Parque de Alta Tecnologia de São Carlos. Nesta mesma cidade também foi construída a primeira edificação com a finalidade de ser uma incubadora, ou seja, não sendo uma estrutura adaptada, a Incubadora do Centro de Desenvolvimento da Indústria Nascente (Cedin). Neste mesmo período, algumas outras incubadoras foram criadas em diferentes cidades como: Campina Grande na Paraíba, Santa Maria no estado do Rio Grande do Sul e Joinville em Santa Catarina, cidade nas quais os $\mathrm{CNPq}$ entendia ser de localidades propícias para o fomento desta atividade. Desta forma houve um crescente desenvolvimento desta atividade no Brasil ao longo dos anos subsequentes.

\subsubsection{Critérios de seleção das empresas para entrar em uma incubadora.}

A incubadora não é um lugar para a empresa ficar indefinidamente, ela é um ponto de partida para o empreendedor iniciar a sua jornada. Com o objetivo de desenvolver um número maior de empresas, o que ocorre geralmente é um processo seletivo, com o intuito de selecionar as empresas que vão participar do programa de formação empreendedora de cada incubadora, após este processo a empresa se torna graduada finalizando o processo de incubação e se lançando no mercado.

De acordo com a Associação Nacional de Entidades Promotoras de Empreendimentos Inovadores (ANPROTEC), uma instituição que reúne incubadoras de empresas, parques tecnológicos, instituições de ensino e pesquisa, órgãos públicos e outras entidades ligadas ao empreendedorismo e à inovação, as regras de seleção de empresas para serem incubadas variam de acordo com cada incubadora, mas pode-se dizer que o prérequisito mais importante é a inovação (ANPROTEC, 2015).

Os autores Farah, Cavalcanti e Passos (2012) identificam as seguintes características nos processos de seleção das incubadoras: aceitam empresas com perfil definido no processo de seleção, realizam análise do perfil do empreendedor, analisam os projetos quanto a viabilidade técnica e comercial sob a ótica de um plano de negócios, analisam os produtos e processos não poluentes e de aceitação social: ao ocupar um espaço coletivo, e procuram estabelecer um mix adequado de empresas na incubadora, de forma a criar uma sinergia entre as empresas incubadas, evitando uma competição entre elas.

Conforme pode-se observar nas explicações dos autores os critérios de seleção objetivam selecionar empresas e empreendedores que atendam determinados pré-requisitos com o intuito de atender aos objetivos dos programas de formação empreendedora de cada incubadora gerando, assim, resultados que apresentem benefícios e o alcance dos objetivos para todas as partes interessadas. 


\subsection{Contabilidade de custos}

A contabilidade de custos tem a sua conceituação voltada ao processo ordenado de registro dos custos de um negócio usando os princípios da contabilidade geral para esta ação (BRUNI; FAMÁ, 2008). Desta forma, entender o que significa custos faz-se necessário.

Os custos de maneira geral são vistos como a entrega de algum ativo buscando-se o alcance de um objetivo. Os autores Bruni e Famá (2008, p. 23), partindo da ótica industrial, conceituam o termo custo como um "gasto relativo a bens ou serviços utilizados na produção de outros bens ou serviços". Martins (2008) corrobora com a definição ao afirmar que:

O Custo é também um gasto, só que reconhecido como tal, isto é, como custo, no momento da utilização dos fatores de produção (bens e serviços), para a fabricação de um produto ou execução de um serviço. Exemplos: a matéria-prima foi um gasto em sua aquisição que imediatamente se tornou investimento, e assim ficou durante o tempo de sua estocagem; no momento de sua utilização na fabricação de um bem, surge o Custo da matéria-prima como parte integrante do bem elaborado. Este, por sua vez, é de novo um investimento, já que fica ativado até sua venda (MARTINS, 2008, p.25).

O autor é bem detalhista em sua explicação, ao demonstrar, de forma bem clara, o instante em que o custo é reconhecido no processo produtivo. Afirma que esta terminologia pode ser usada em empresas de outros segmentos, tais como, serviços, comércio e entidades financeiras ao considerarem os custos que imediatamente se transformam em despesas, sem que para esta haja a necessidade de estocagem nestes segmentos empresariais (MARTINS, 2008).

Neste estudo, a utilização do termo custo tem a finalidade única de atingir os objetivos específicos, neste caso, a mensuração das possíveis vantagens no aspecto financeiro, que a pesquisa irá demonstrar ao se abrir uma empresa em uma incubadora de empresas, além dos dispêndios necessários para abrir uma empresa no país, desta forma, limita-se o uso da terminologia de custos agrupando as classificações em um único termo "gasto" que irá nortear-nos em direção ao significado de sacrifício financeiro.

\subsection{Custo de abertura de empresa no Brasil}

Neste tópico o presente artigo apresenta os resultados de uma pesquisa feita pela FIRJAN no ano de 2010 denominada "Estudos para o Desenvolvimento do Estado do Rio de Janeiro" na qual foi feito um levantamento, descrição e comparação dos custos de abertura de uma empresa em todos os estados do país. Sintetizou-se os resultados da pesquisa nas figuras 2, 3 e 4 abaixo ilustram estas informações. 
Figura 2: Custo de abertura de empresas no Brasil por unidade da federação

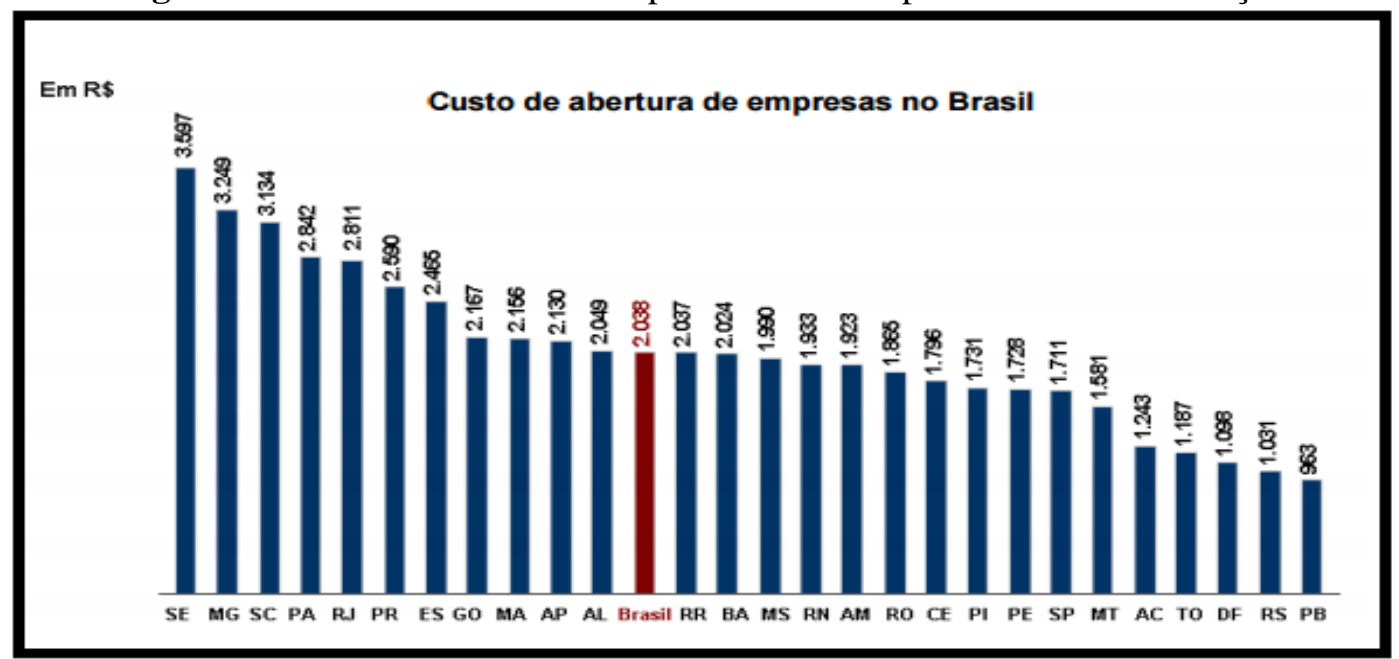

Fonte: FIRJAN (2010).

Como observa-se na figura 2 acima, o custo médio de abertura de uma empresa no Brasil, considerando todas as etapas e taxas nos 27 estados, todos os portes e os setores de comércio, serviço e indústria é de R \$ 2.038. Dentre os estados, o maior custo é registrado em Sergipe, com $\mathrm{R} \$ 3.597$ e o menor na Paraíba, com $\mathrm{R} \$ 963$, uma variação de $274 \%$.

A figura 3, abaixo, detalha percentualmente a formação do custo médio de abertura de empresas que empresário terá que desembolsar em cada órgão.

Figura 3: Custo de abertura de empresas no Brasil por tipo de gasto

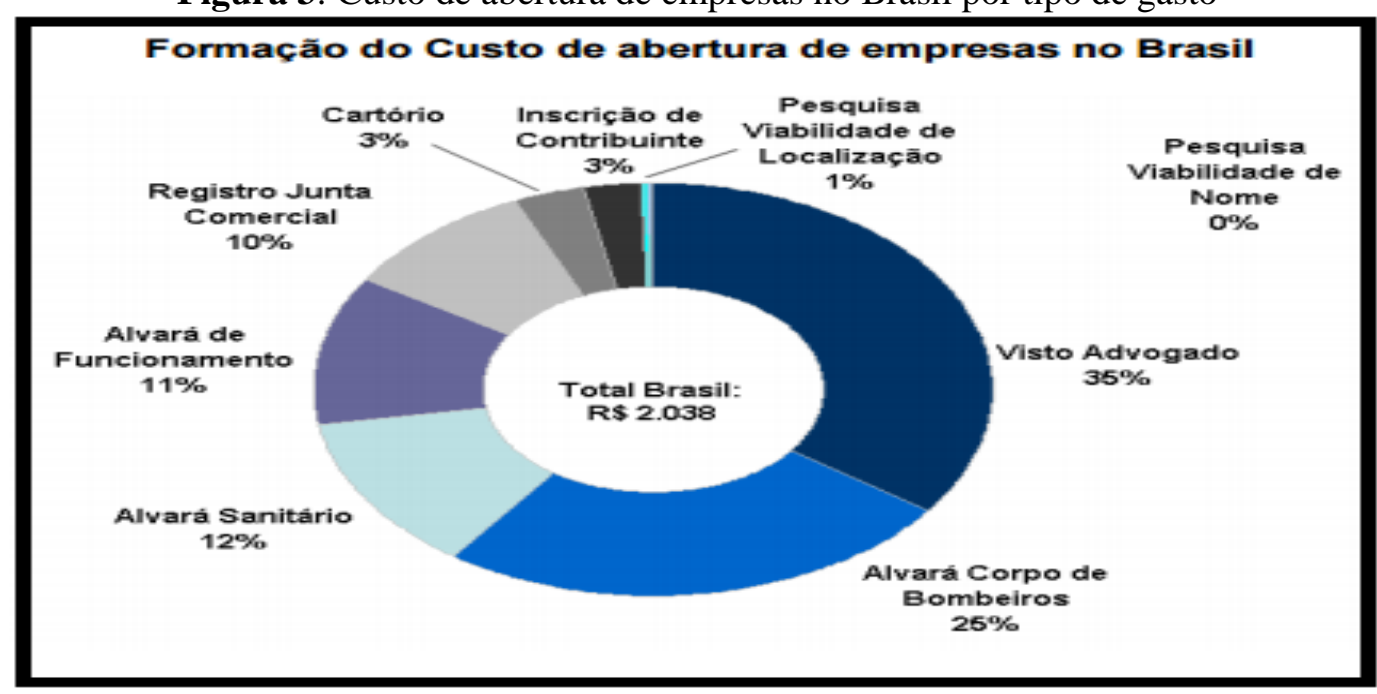

Fonte: FIRJAN (2010).

Por fim, a figura 4, abaixo, compara os custos do Brasil com os custos dos dez países do mundo com maior facilidade para a abertura de empresas. Destaca-se o alto custo de abertura, é fator desestimulante ao empreendedor que almeja iniciar um negócio no Brasil. 
Figura 4: Custo de abertura de empresas no Brasil e em mais 10 países

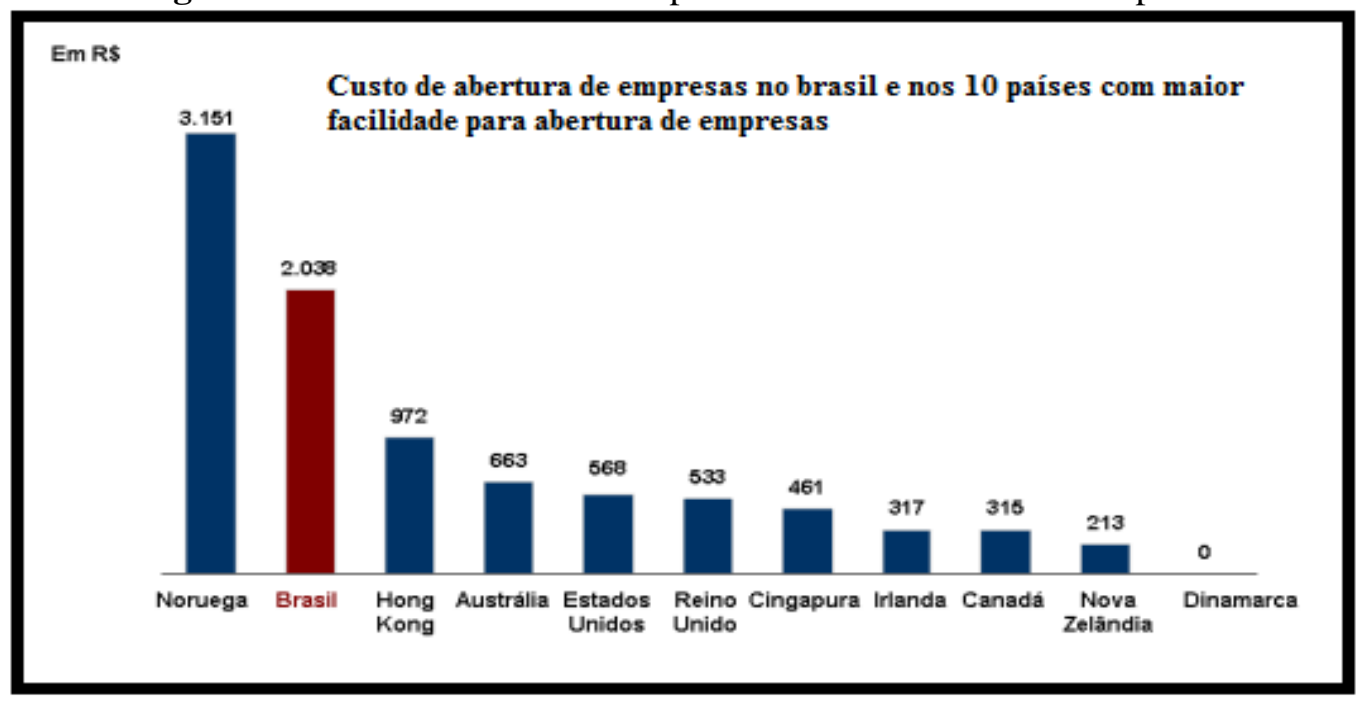

Fonte: FIRJAN (2010).

\section{ESTUDO DE CASO}

O presente estudo foi realizado no Centro Regional de Inovação e Transferência de Tecnologia (CRITT), sendo este o Núcleo de Inovação Tecnológica (NIT) da Universidade Federal de Juiz de Fora (UFJF), vinculado à Pró-Reitoria de Pós-Graduação, Pesquisa e Inovação (PROPGPI). Criado em abril de 1995, por meio da Resolução 16/1995 e qualificado como NIT pela Resolução 31/2005, ambas do Conselho Superior (Consu), o CRITT está situado no campus da UFJF e conta com uma área de, aproximadamente, 1.300 metros quadrados.

A entidade possui como valores: excelência nas atividades, comprometimento, melhoria contínua, pró-atividade, comportamento ético e responsabilidade social. Contribuir, como instituição cidadã, para a interação Universidade/Sociedade, através da gestão do conhecimento e da transferência de tecnologias e de soluções inovadoras, é a missão da empresa. E sua visão é fortalecer-se como referência nacional em inovação tecnológica e incubação de empresas e contribuir efetivamente para o desenvolvimento da Zona da Mata Mineira.

Sua atuação envolve a prospecção de projetos da UFJF para empreendedores e empresas que buscam assessoria para o desenvolvimento de novos produtos ou aperfeiçoamento de processos de produção em diferentes áreas. Entre as suas atribuições estão o gerenciamento da política de inovação da UFJF e a coordenação da Incubadora de Base Tecnológica. O CRITT é composto por três setores finalísticos: Incubadora de Base Tecnológica, Transferência de Tecnologia e o Treinamento e, também por sete setores de apoio: Administrativo e Financeiro, Comunicação e Marketing, Proteção ao Conhecimento, Qualidade, Recursos Humanos e Tecnologia da Informação.

Desde o ano de 2001, a entidade tem seu sistema de gestão da qualidade certificado pela NBR ISO 9001, atualmente na versão 2008, padrão internacional para a gestão da qualidade, o que evidencia a excelência, padronização e melhoria contínua do sistema de gestão da qualidade do centro.

A pesquisa foi realizada no setor finalístico denominado de Incubadora de Base Tecnológica (IBT), que segundo CRITT (2015) tem o objetivo de fornecer apoio para 
empreendedores que buscam iniciar um negócio e desenvolver produtos, serviços ou processos que apresentem grau de tecnologia e inovação.

De acordo com o CRITT (2015) o IBT tem como características: apoiar o desenvolvimento de produtos e processos inovadores de base tecnológica e design; dar suporte gerencial às empresas incubadas, buscando melhor articulação de seus recursos para a otimização da qualidade dos produtos, processos e resultados; acompanhar continuamente do plano de negócios, estratégias e plano de ação das empresas; fornecer ambiente planejado e estruturado ao desenvolvimento das inovações; avaliar as empresas quanto aos eixos tecnológico, mercado, financeiro, empreendedor e de gestão; e acompanhar e divulgar editais de fomento para a captação de recursos para a elaboração, submissão e gestão de projetos.

O processo de seleção, segundo o CRITT (2015) é realizado através da publicação de um edital, no qual é estabelecido que as empresas de base tecnológica poderão se instalar no CRITT durante um período de até três anos, renovável mediante solicitação devidamente justificada, desde que apresentem uma proposta que será julgada segundo os seguintes critérios: conteúdo tecnológico e grau de inovação dos produtos, serviços ou processos a serem criados, possuir viabilidade técnica e econômica; possuir viabilidade mercadológica, existência de capacidade técnica e gerencial do proponente, e potencial de interação do empreendimento com as atividades desenvolvidas na UFJF.

Desta forma, os empreendedores que almejam incubar a sua empresa no CRITT deverão cumprir as exigências do edital e ao serem avaliados, conseguir aprovação nos cinco eixos descritos acima.

O presente estudo compara as vantagens referentes aos custos de abrir uma empresa em uma incubadora com a abertura diretamente no mercado. Para evidenciar esta comparação foi entrevistado o gestor do IBT, um economista de formação que está no CRITT a sete anos e atua na função de responsável pelo IBT a cinco anos, corroborado pelas declarações dos empresários dos negócios incubados no CRITT, com amostra de três empresas incubadas de um total de onze que estão atualmente na incubadora. A escolha de entrevistar os empresários bem como o gestor foi motivada pela possibilidade de comparação, assim como complementação entre as respostas. Foi utilizado questionário semiestruturado para a captação das informações necessárias.

Inicialmente, um dos pontos observados foi o papel do CRITT no incentivo ao empreendedorismo, bem como, no incentivo a abertura das empresas. As respostas obtidas sinalizaram que dois processos realizados pela incubadora apoiam o empreendedorismo, a saber: IBT, cujas características foram descritas num momento anterior, e o Programa de Formação Empreendedora que dissemina a cultura do empreendedorismo e da inovação, assessora empreendedores no estudo de viabilidade de seus negócios, capacita futuros empreendedores por meio de cursos de planejamento empresarial e construção do plano de negócios, além de captar projetos com potencial tecnológico para inserção na IBT. Foram citadas ainda, maior visibilidade para as empresas que já existiam e apoio estrutural e técnico para o desenvolvimento de negócios e produtos.

A pergunta seguinte buscou identificar outros custos envolvidos na abertura de empresas, além dos incorridos com o processo burocrático. As respostas foram baseadas no último edital aberto para seleção, que indicou um dispêndio de $\mathrm{R} \$ 100,00$ com taxa de inscrição, além de um custo denominado "despesa de incubação" que é a taxa recolhida dos empresários incubados, na qual estão contidos todos os gastos que os empresários terão que desembolsar durante o período que estiverem incubados, esta taxa é mensal e estava orçada no último edital em $\mathrm{R} \$ 34,00 / \mathrm{m}^{2}$ do espaço utilizado por cada incubadora, que variava de 18 a 32 metros quadrados por box. Os empresários indicaram, ainda, gasto com cursos de formação empreendedora, considerado por eles como investimento em capacitação. 
Foi perguntado se por estarem localizadas dentro de uma incubadora, as empresas obtiveram alguma isenção de alguma taxa de abertura de empresa em algum órgão público e todas as respostas sinalizaram que não, o que demonstra uma paridade com as demais empresas.

A pergunta seguinte identificou o uso de recursos e serviços compartilhados pelas empresas incubadas. Ao entrarem de fato na incubadora, as empresas compartilham um espaço físico, dividido em box individuais, e também as áreas de uso comum, a saber: auditório com capacidade para quarenta pessoas, salas de reuniões, refeitório, laboratório de informática, bem como o uso irrestrito de internet, luz, água, Imposto Predial e Territorial Urbano (IPTU), serviço de telefonista em horário comercial e limpeza, o que diminui os custos fixos dos empresários. Serviços estes que estão inclusos na despesa de incubação.

No edital um fator relevante, avaliado no processo de incubação, é a capacidade de investimento feita pelos sócios da empresa participante. Uma ação adotada pelo CRITT que auxilia na redução dos investimentos com capital próprio dos empreendedores é a assessoria na captação de recursos em órgão de fomento para as empresas incubadas.

\section{CONSIDERAÇÕES FINAIS}

O estudo de caso atinge o objetivo proposto, que foi identificar os possíveis benefícios de se iniciar um negócio em uma incubadora de empresas, e conclui-se que, no momento inicial em que os empreendedores decidem abrir um negócio em uma incubadora de empresas, os mesmos terão que desembolsar uma quantia maior, visto que, além das taxas decorrentes dos processos burocráticos existentes, eles terão que fazer um desembolso com taxas para participar do processo seletivo, bem como de cursos de empreendedorismo.

Destaca-se, porém, que ao longo do tempo em que estiverem incubados, existem, claramente, vantagens ao empreendedores que decidem abrir uma empresa dentro de uma incubadora, tanto em diminuição dos custos, pois, os valores desembolsados mensalmente pelos serviços oferecidos por estas são menores em comparação aos encontrados no mercado, quanto em benefícios oferecidos aos empreendedores, como: assessorias técnicas, operacionais e capacitação, o que garante maiores índices de sobrevivência das empresas, após o período de incubação.

A partir desta pesquisa o trabalho abre algumas possibilidades para que estudos futuros possam ser feitos como realizar uma pesquisa que envolva detalhadamente os custos decorrentes no processo, pesquisa e desenvolvimento de um produto ou que relacione todos os valores desembolsados pelas empresas para estruturarem-se nos primeiros anos do negócio. 


\section{REFERÊNCIAS}

ANPROTEC - Associação Nacional de Entidades Promotoras de Empreendimentos Inovadores. Perguntas frequentes. Disponível em: <http://anprotec.org.br/site/incubadorase-parques/perguntas-frequentes/>. Acesso em:12 Jul 2015.

BANCO MUNDIAL. Doing Bussiness. 2014. Disponível em: <http://portugues.doingbusiness.org/data/exploreeconomies/brazil/> Acesso em 20 Jul 2015.

BRUNI, A. L; FAMÁ, R. Gestão de custos e formação de preços: com aplicações na calculadora HP 12C e Excel. 5. ed. São Paulo: Atlas, 2008.

CERVO, Amado L; BERVIAN, Pedro A. Metodologia Científica. 5. ed. São Paulo: Pearson Prentice Hall, 2002.

CRITT (Centro Regional de Inovação e Transferência de Tecnologia). Site Institucional. Disponível em http://www.ufjf.br/critt/incubacao-de-empresas/. Acesso em:30 ago 2014.

DEGEN, R. J. O empreendedor: empreender como opção de carreira. São Paulo: Pearson Prentice Hall, 2009.

DOLABELA, F. O segredo de Luísa. Rio de Janeiro: Sextante, 2008.

DORNELAS, José C. A. Transformando ideias em negócios. 2.ed. 7. reimpr. Rio de Janeiro: Elsevier, 2005.

FARAH, O. E; CAVALCANTI, M; PASSOS, L. M. Empreendedorismo: estratégia de sobrevivência para pequenas empresas. São Paulo: Saraiva, 2012.

FIRJAN. Quanto custa abrir uma empresa no Brasil? Disponível

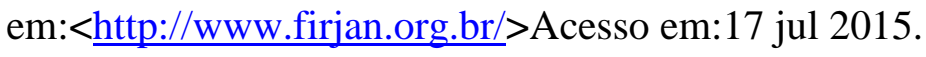

JABBOUR, C. J. C.; DIAS, P. R.; FONSECA, S. A. As incubadoras de empresas como redes empresariais pró-inovação. Bauru: XI SIMPEP, 2004.

MALHOTRA, Naresh K. et al. Introdução à pesquisa de marketing. São Paulo: Pearson Prentice Hall, 2005.

MARTINS, E. Contabilidade de custos. 9.ed. 7. reimpr. São Paulo: Atlas, 2008.

MENEZES, G. G. Empreendedorismo: desde o ensino fundamental capacitando futuros empregadores. Monografia (Graduação em Administração). Faculdade Metodista Granbery. Juiz de Fora, 2012.

SEBRAE-RS. 7Passos para abrir uma empresa. Disponível em: <http://www.sebraers.com.br/index.php/7-passos-para-abrir-minha-empresa> Acesso em 15 jul 2015.

SMPE (Secretaria da Micro e Pequena Empresa da Presidência da República). Site Institucional. Disponível em: 〈http://smpe.gov.br/> Acesso em 15 jul 2015. 
YIN, Robert K. Estudo de caso: planejamento e métodos. 3.ed. Porto Alegre: Bookman, 2005. 